\title{
Development of Branched Aromatic Polyester Polyols from PET
}

\author{
Marin Boyadzhiev, Rainer Langenstraßen, Rozeta Eftimova, \\ Sanchy Nenkova, Gerhard Behrendt
}

\section{Zusammenfassung}

Diese Arbeit befasst sich mit einer neuen Klasse verzweigter aromatischer Polyesterpolyole (APP), die auf PET-Abfällen basieren und für die Herstellung hochwertiger Polyurethane entwickelt wurden. Dieses Ziel wurde durch eine modifizierte Umesterung von PET durch eine Glykolmischung mit einem geringen Anteil Triolen erreicht. Es wurde eine Reihe verzweigter APP mit Hydroxylzahlen im Bereich von 260 bis $380 \mathrm{mg}$ $\mathrm{KOH} / \mathrm{g}$ und Hydroxyl-Funktionalitäten zwischen 2,00 und 2,30 erhalten. Die Viskosität der Produkte steigt im Bereich der Funktionalität von 2,03 bis 2,12 geringfügig und darüber stärker an. Für jede Reihe der APP mit Hydroxylzahlen von 260, 320 bzw. $380 \mathrm{mg} \mathrm{KOH/g}$ wurde bezüglich der Viskosität, der Langzeitstabilität und der Hydroxyl-Funktionalität ein Eigenschaftsoptimum gefunden. APP mit höherer Hydroxyl-Funktionalität können zur Herstellung von Polyurethan-Gießharzen und jene mit niedrigeren Hydroxylzahlen für Beschichtungen, z. B. von Leder, verwendet werden.

\begin{abstract}
This paper is directed to the development of a new type of branched aromatic polyester polyols (APP) based on PET wastes designed to produce high quality polyurethanes (PUR). To this end, a modified transesterification of PET by a glycol mixture was used and simultaneously small amounts of triols were incorporated into the reaction mixture. By this method, a series of branched APP's with hydroxyl numbers in the range of 260 to $380 \mathrm{mg} \mathrm{KOH} / \mathrm{g}$ and hydroxyl functionalities between 2.00 and 2.30 was received. The viscosity of the products increased slowly with the functionality in the range of 2.03 to 2.12 and sharper beyond this value. An optimum of properties was found in each series of APP with hydroxyl numbers of 260, 320, and $380 \mathrm{mg} \mathrm{KOH} / \mathrm{g}$, resp. with respect of viscosity, long term stability and hydroxyl functionality. APP with a higher hydroxyl functionality are useful to produce cast polyurethane resins, those with lower hydroxyl numbers for coatings, e. g. of leather.
\end{abstract}

\section{Introduction}

During the production and processing of polyethylene terephthalate (PET), e. g. in the production of bottles, fibres, or building materials, as well as after the use of PET articles, wastes arise to a great extent. Wastes are presently used in physical recycling (e. g. bottle to bottle process) and chemical recycling (receiving raw materials or polyols). We consider here only the way of chemical recycling to produce polyols. According to Grigsby [1,2] PET wastes are reacted under pressure with diethylene glycol (DEG), occasionally other glycols and additives having higher functionality, e. g. glycerol, are introduced into the reaction mixture. In a second step, ethylene glycol (EG, MEG) is partly distilled off. Peterson [3] describes the reaction of PET with DEG and/or other glycols in horizontal stirring reactors.

We want to report here on a new route to produce a new type of APP. This process to produce APP, e. g. from PET bottles or production wastes, or of wastes of the German »Duales System «, was developed at the University of Applied Science (Technische Fachhochschule) Wildau, Germany, in cooperation with the University of Chemi- cal Technology and Metallurgy, Sofia, Bulgaria. A summary of basic results was given previously by Evtimova et al. [4]. Furthermore, the process to produce linear and branched APP from PET production wastes and flakes from bottle recycling was developed as a continuous one [5].

\section{Experimental part}

Materials used for producing APP and PUR on their basis are:

- DEG (PUR quality of at least $98 \%$ by BASF AG),

- Glycerol (least 99.8 \%, by RME GmbH Schwarzheide),

- Dibutyl-tin-dilaurat (DBTL) (synthesis quality, 98\%, by Nitroil Performance Chemicals, Hamburg),

- Adipic acid (at least $99.6 \%$ purity, by BASF AG),

- PET granulate (by NEO Group, Klaipeda) or flakes from bottle recycling (by Texplast GmbH Wolfen),

- Isocyanate: pure MDI (by Puralis GmbH) and polymeric MDI (Lupranat ${ }^{\circledR}$ M20S of BASF AG). 
The general route to produce branched APP is as follows:

Into a 101 stainless steel reactor with heating oil mantle, stirrer and FTIR spectrometer immersion probe (ReactIR 4000 from Mettler Toledo GmbH, Giessen, Germany), the calculated amounts of DEG and DBTL are introduced. While heating this mixture to about $165^{\circ} \mathrm{C}$ the reactor is constantly flushed with nitrogen. After said temperature is reached, the calculated amount of adipic acid is introduced in portions by the solid feed. After completing the addition, the temperature is raised to $220^{\circ} \mathrm{C}$ and water is distilled off. After the distillation ceased, another portion of DEG mixed with glycerol and the calculated amount of PET are added. The temperature is raised to $250^{\circ} \mathrm{C}$ and kept there for 4.5 hours while a pre-calculated amount of monoethylene glycol (MEG) is distilled off. After this amount is obtained, the temperature is reduced and the APP recovered via a filtering unit. The process is controlled by the amount of the different distillates obtained. The APP is characterized by the following methods:

- Hydroxyl number by titration according to DIN 53240,

- Acid number by titration according to DIN 53402,

- Viscosity using a Rheostress 300 viscosimeter (ThermoHaake, Karlsruhe, Germany) in the rotation and oscillation modes.

The scaling up was performed in 1001 and 4001 stainless steel reactors using a similar processing route.

Polyurethane systems based on the APP are developed to form rigid foams, cast resins or coatings.

The polyurethane films were produced by hand casting technique on siliconized paper or using the Mathis ${ }^{\circledR}$ Lab Dryer ${ }^{\circledast}$ to produce the films under controlled conditions (temperature, time). The polyurethane casts were produced by hand mixing, degassing and pouring into a respective mould. Rigid foams were produced either by manual mixing using a stirrer with $6000 \mathrm{rpm}$. The foams were produced with a density of 40 to $400 \mathrm{~g} / \mathrm{dm}^{3}$. Foams were alternately produced on a two component foaming machine using a low pressure machine of Lackfa $\mathrm{GmbH}$.

The polyurethanes were characterized by:

- dynamic-mechanical analysis (Netzsch DMA 242),

- differential scanning calorimetry (Netzsch DSC 204),

- mechanical testing (Zwick Materialprüfmaschine Z 020) for tensile strength, elongation at break and flexural strength,

- Shore D hardness (Shore Tester),

- Microscopy by a scanning electron microscope (SEM).

\section{Results and discussion}

The general route to produce APP from PET is known to be a transesterification of the high molecular weight PET by glycols with simultaneous cleavage of the macromolecular chains according to the following equation (figure 1):<smiles>CCCCC(C)OCCOC(=O)c1ccc(C(C)(C)OCCO)cc1</smiles><smiles>CC[C@H](OCCOCCOC(=O)c1ccc(C(=O)OCCOCCO)cc1)[C@@H](C)OCCO</smiles>

Figure 1. General equation of PET transesterification

Such transesterifications employing one or more glycols were described earlier $[6,7]$. The process was performed with or without the use of catalysts or with one glycol both as a reaction partner and to be liberated or more glycols of which in some processes two are distilled off so as to increase the rate of reaction. As a starting material PET wastes, i. e. oligocondensates of the production process, maybe used as a single reaction partner [8] or as an additional processing aid [9]. Generally, in this process, the lower molecular weight glycol is liberated in a balance process, so that this has to be constantly eliminated to support the transesterification and receive oligomers with the desired number of repeating structural units from 1 to 8 . Some of transesterification reagents or products remain in the reaction mixture, generally between 3 to $10 \%$ by weight and serve as a solvent for the oligomers produced. It has to be considered in terms of the stability of the APP and for the quality of the polyurethanes produced from them that the amount of MEG is kept as low as possible. The presently produced APP are strictly linear products without any branching so that crosslinked polyurethanes are solely produced by formulation.

In our approach we substituted part of the glycol, in general DEG was used, by a triol so as to receive branching in the oligomer chains. Further, part of the aromatic acid was substituted by an aliphatic acid to control the viscosity of the produced APP. Furthermore, we investigated several catalysts or catalyst systems in combination with the temperature of the reaction to reduce the time of transesterification [10].

The aliphatic dicarboxylic acid is further introduced into the oligomeric chain to control the properties of specialty polyurethanes and, especially, to reduce the brittleness of polyisocyanurates produced on their base at high isocyanate indexes.

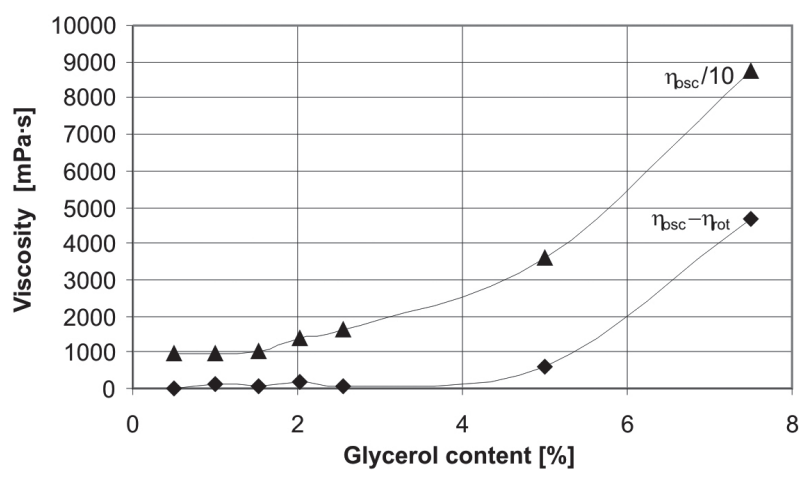

Figure 2. Dependence of the viscosity $\eta$ of polyols on glycerol content (hydroxyl number $240 \mathrm{mg} \mathrm{KOH/g,} 12$ \% adipic acid) 
The APP is produced in three categories according to the application in polyurethane systems which are qualified in terms of their hydroxyl number. Thus, we developed three families of APP with hydroxyl numbers of 240,320 and $380 \mathrm{mg} \mathrm{KOH} / \mathrm{g}$. Of these, the first is mainly designed for application in duromer foams, polyisocyanurates, or coatings, the second for panel foams or cast resins, and the latter for typical rigid foams, e. g. for pipe insulation. Another type of APP was developed with lower hydroxyl numbers such as $180 \mathrm{mg} \mathrm{KOH} / \mathrm{g}$ to be employed in cover coatings for leather in aliphatic diisocyanate systems [11].

In the series with the hydroxyl number adjusted to $240 \mathrm{mg} \mathrm{KOH} / \mathrm{g}$ the amount of glycerol was varied from 0 to $8 \%$. Increasing the amount of glycerol leads to an increase of the functionality of the polyols produced from 2.03 to 2.15 . As it is shown in figure 2 the viscosity of the polyols with $12 \%$ of adipic acid rises rather linearly to about $5 \%$ of glycerol and starts to increase steeper at higher amounts incorporated into the chain of the oligomers. The reason for the steeper increase may derived from the second curve of figure 2 in which the difference of the viscosities measured by rotational and oscillational mode is shown. This curve shows a significant sharp increase at this point hinting to another type of origin of the viscosity. While the rotational mode of the viscosity only corresponds to the Newton'ian mode the oscillational mode reflects the structural viscosity as well. The difference is, therefore, a qualitative measure for the non-Newton'ian part of the viscosity. This increases sharply at the addition of about $5 \%$ of glycerol showing an increasing portion of structural viscosity. Any structural viscous materials represent problems in the handling of them in the polyurethane machinery and have to be avoided so that the amount of branching of the APP of this type is limited to a maximum of $5 \%$ or a hydroxyl functionality of 2.12.

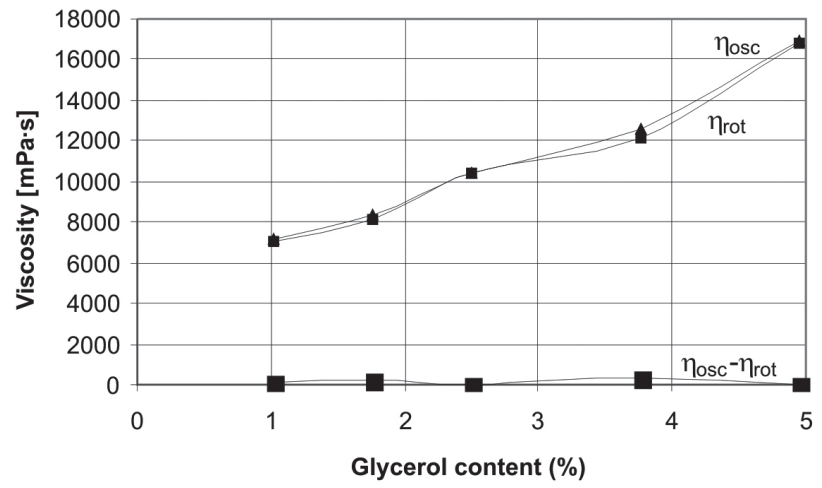

Figure 3. Dependence of the viscosity $\eta$ of polyols on glycerol content (hydroxyl number $240 \mathrm{mg} \mathrm{KOH/g,} 16 \%$ adipic acid)

Figure 3 shows that higher functionality corresponds with a higher viscosity of the polyols with $16 \%$ of adipic acid reaching values up to $17,000 \mathrm{mPa} \cdot \mathrm{s}$. The difference in the values of viscosity in the oscillation and rotation mode of the polyols does not exceed $400 \mathrm{mPa} \cdot \mathrm{s}$ which shows that there is generally little content of molecular superstructures up to the investigated area of $5 \%$ of glycerol. This makes the polyols of the respective range of functionalities well suitable for polyurethane production. The differences of the viscosity measurements with both modes are solely dependent on the amount of aliphatic dicarboxylic acid incorporated while the formation of non-Newton'ian viscosity depends on the amount of triol, here glycerol, used.. A higher amount of adipic acid used in the production of APP, thus, leads to a decrease of the viscosity and simultaneously to a decrease of the content of molecular superstructures.

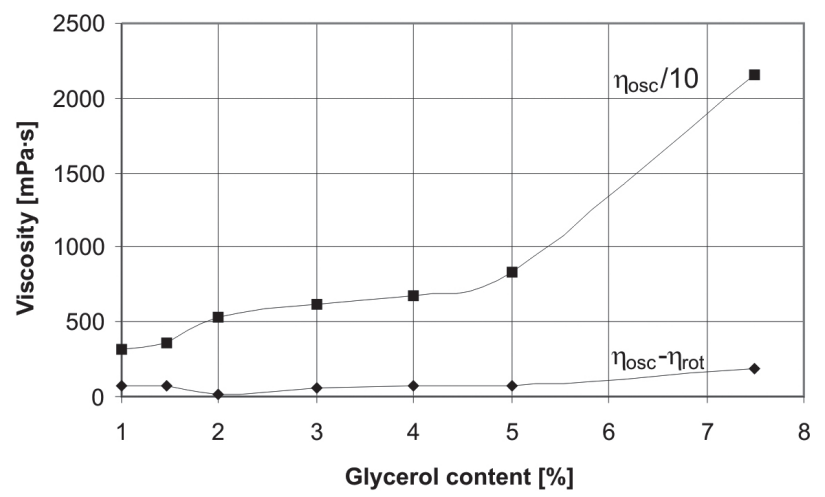

Figure 4. Dependence of the viscosity $\eta$ of polyols on glycerol content (hydroxyl number $320 \mathrm{mg} \mathrm{KOH/g,} 6 \%$ adipic acid)

In the third series with the hydroxyl number of the APP adjusted to $320 \mathrm{mg} \mathrm{KOH} / \mathrm{g}$ the amount of glycerol was increased from 0 to $8 \%$. This leads again to a higher hydroxyl functionality but also to a rise in the value of the viscosity up to $20,000 \mathrm{mPa} \cdot \mathrm{s}$. As it is shown in figure 4 the difference in the values of the viscosity in the oscillation and rotation mode of the polyols is very low in the range up to $5 \%$ of glycerol which does not allow an interpretation as it is close to the standard equipment error. The slight increase in viscosity after passing the mark of $5 \%$ of glycerol is very much lower than in the previous series and does not exceed of $400 \mathrm{mPa} \cdot \mathrm{s}$ which is a much smaller increase than in the first series showing that lower molecular weights of the oligomeric chains and a slightly increased amount of glycol solvents hinder the formation of structural viscosity. Based on that the application of the polyols depends only on the viscosity values.

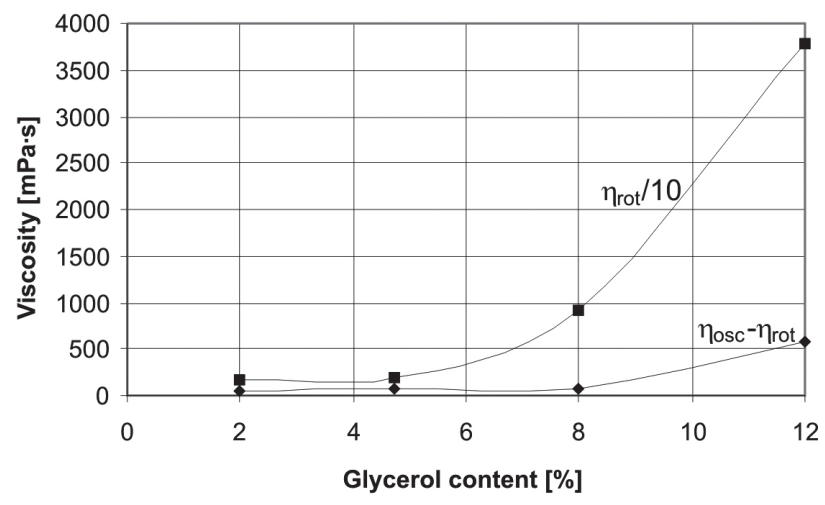

Figure 5. Dependence of the viscosity $\eta$ of polyols on glycerol content (hydroxyl number $380 \mathrm{mg} \mathrm{KOH/g}$, no adipic acid) 
In the forth series with APP of hydroxyl numbers in the range of $380 \mathrm{mg} \mathrm{KOH} / \mathrm{g}$, the amount of glycerol was increased from 0 to $12 \%$. The value of the viscosity rises up to $35,000 \mathrm{mPa} \cdot \mathrm{s}$. As is shown in figure 5 the difference in the values of the viscosity in the oscillation and rotation mode of the polyols is increasing to slightly more than $500 \mathrm{mPa} \cdot \mathrm{s}$. The increase is very low in the area up to $8 \%$ of glycerol and is only slightly exceeding the standard error of the instrument. Beyond $8 \%$ of glycerol in the formulation the increase becomes more pronounced. Here again, this behaviour of the viscosity over functionality shows a dependence on the structural part of the viscosity by increasing the latter.

In another series, formulations to produce polyols with such a hydroxyl number were developed without using adipic acid. In this series, the development of a higher degree of structural viscosity was observed at a hydroxyl functionality of 2.12 , i. e. at a content of glycerol of $9 \%$. This shows again that the incorporation of the aliphatic dicarboxylic acid into the oligomer chains has very little effect on the build-up of structural viscosity and is only responsible for the adjustment of the viscosity of the polyol with respect to its field of application.

As it can be seen in all the series employing different hydroxyl numbers the viscosity rised with the degree of branching in the polyol chains and decreases with increasing the amount of aliphatic dicarboxylic acid built into the oligomer chains.

The APP produced in this way are to be used for non-porous polyurethanes, e. g. solid resins, casts, sealants and especially coatings. One field of application is the use of these APP in coating formulations for leather and fibres.

Otherwise, they maybe used for cast resins or reinforced casts to produce polyurethane heels. To produce such the following lab formulation VS 249 was used: APP (OH No. $\left.259 \mathrm{mg} \mathrm{KOH} / \mathrm{g}, \mathrm{f}_{\mathrm{n}}=2.08\right) \quad 97.1$ parts Titanium dioxide (micronized) Sodium aluminium silicate $\left(\right.$ Baylit $^{\circledR}$ ) Lupranat ${ }^{\circledR}$ M20S

0.6 parts

2.3 parts 60.0 parts

The components were degassed and mixed by hand to give a clear liquid and cast into moulds at room temperature. Curing was performed for 8 hours at $120^{\circ} \mathrm{C}$. After cooling to room temperature the casts were recovered from the moulds, subjected to 14 days of after-curing and tested. The results of the testing is depicted in table 1. Further results on systematic investigations with cast polyurethanes obtained from APP of varying properties and different isocyanates will be given in a forthcoming paper $[12,13]$.

\begin{tabular}{|l|l|r|}
\hline Property & Dimension & Value \\
\hline Glass transition (DSC) & ${ }^{\circ} \mathrm{C}$ & 53.6 \\
\hline Glass transition region (DMA) & ${ }^{\circ} \mathrm{C}$ & $31-72$ \\
\hline Tensile strength & $\mathrm{N} / \mathrm{mm}^{2}$ & 116.7 \\
\hline Elongation at break & $\%$ & 1.48 \\
\hline Flexural strength & $\mathrm{N} / \mathrm{mm}^{2}$ & 177.8 \\
\hline Flexural elastic modulus & $\mathrm{N} / \mathrm{mm}^{2}$ & 3476 \\
\hline
\end{tabular}

Table 1: Properties of cast polyurethanes of lab formulation VS249
Further, from APP thus produced protective coatings for natural and artificial leather were prepared on the Mathis LabCoater $^{\circledR}$. To this end, an APP with a hydroxyl number of $228 \mathrm{mg} \mathrm{KOH} / \mathrm{g}$ and a functionality of 2.08 (i. e. a glycerol content of 5\%) was used. The lab formulation VS322 was as follows:

APP (OH No. $228 \mathrm{mg} \mathrm{KOH} / \mathrm{g}, \mathrm{f}_{\mathrm{n}}=2.08$ )

Titanium dioxide (micronized)

93.2 parts

1.0 parts

Iron dark brown pigment

4.7 parts

Sodium aluminium silicate $\left(\right.$ Baylit $^{\circledR}$ )

1.1 parts

4,4'-dicyclohexylmethane diisocyanate

52.0 parts

\begin{tabular}{|l|l|r|}
\hline Property & Dimension & Value \\
\hline Glass transition (DSC) & ${ }^{\circ} \mathrm{C}$ & 45 \\
\hline Glass transition region (DMA) & ${ }^{\circ} \mathrm{C}$ & $25-65$ \\
\hline Tensile strength & $\mathrm{N} / \mathrm{mm}^{2}$ & 110 \\
\hline Elongation at break & $\%$ & 2.1 \\
\hline Flexural strength & $\mathrm{N} / \mathrm{mm}^{2}$ & 190 \\
\hline
\end{tabular}

Table 2: Properties of films obtained from lab formulation VS322

The APP were chosen due to their UV stability. The mechanical testing resulted in the values depicted in table 2 .

Further investigations were made with foaming. Two different densities were chosen, i. e. $50 \mathrm{~g} / \mathrm{dm}^{3}$ and $130 \mathrm{~g} /$ $\mathrm{dm}^{3}$ using APP of different hydroxyl functionality [14]. The formulations are given in table 3 , the properties obtained in table 4.

\begin{tabular}{|l|r|r|}
\hline Substance & K 3105061-50 & K 2909065-130 \\
\hline APP $(\mathrm{OH} 380)$ & 93.5 & 0 \\
\hline APP $(\mathrm{OH} 244)$ & 0 & 95.4 \\
\hline PC Cat NP 40 & 0.9 & 0.9 \\
\hline DMEOA & 0.1 & 0.1 \\
\hline TEGOSTAB ${ }^{\circledR}$ B8433 & 1.0 & 0.9 \\
\hline Water & 4.5 & 0.5 \\
\hline Pentane & 0 & 2.2 \\
\hline Lupranat ${ }^{\circledR}$ M2OS & 163.5 & 65.0 \\
\hline
\end{tabular}

Table 3: Foam lab formulations

The foams were produced by hand mixing in amounts to be sufficient to fill an 81 mould of aluminium coated with a separating wax. After foaming up the moulds were closed and kept at room temperature for one hour before being opened. The blocks were demoulded and left at room temperature for seven days before cutting into standard cubes or rods. Testing was performed after further two days conditioning at room temperature. The results of the mechanical testing are presented in table 4 .

\begin{tabular}{|l|l|r|r|}
\hline Property & Dimension & K 3105061-50 & K 2909065-130 \\
\hline $\begin{array}{l}\text { Dimensional } \\
\text { change } \\
\text { at } 120^{\circ} \mathrm{C}\end{array}$ & $\%$ & +0.94 & +0.52 \\
\hline $\begin{array}{l}\text { Dimensional } \\
\text { change } \\
\text { at } 150^{\circ} \mathrm{C}\end{array}$ & $\%$ & - & +0.65 \\
\hline $\begin{array}{l}\text { Flexural } \\
\text { strength }\end{array}$ & $\mathrm{N} / \mathrm{mm}^{2}$ & 0.86 & 1.89 \\
\hline $\begin{array}{l}\text { Flexural elastic } \\
\text { modulus }\end{array}$ & $\mathrm{N} / \mathrm{mm}^{2}$ & 13.4 & 29.3 \\
\hline
\end{tabular}

Table 4: Mechanical properties of foams 
As can be seen from the tables 1 to 4 the new developed APP lead to polyurethanes with exceptional high property values. Especially the high dimensional stability of the foams and the high flexural strength of the cast resins is attributed to the new structure of the APP [15]. Furthermore, the investigation into coatings including final coatings of leather shows that by the development of a special type of such APP highly scratch resistant and UV stable coatings were obtained when using an appropriate diisocyanate. Thus, these new APP offer new opportunities to develope and apply specialty polyurethanes with high quality levels.

\section{Conclusions}

New branched aromatic polyester polyols were obtained by incorporating small portions of glycerol into the oligomer chain of such polyols during the transesterification reaction of PET. By adjusting the ratio of PET, DEG, adipic acid and glycerol as a branching agent in the reaction mixture long time stable aromatic polyester polyols with adjustable properties such as hydroxyl number, branching and viscosity at very low acid number were obtained. In thorough investigations of three series of such polyols in the hydroxyl number range of 240, 320, and $380 \mathrm{mg} \mathrm{KOH} / \mathrm{g}$ the optimum conditions were determined by the viscosity of the resulting products and by the structural part of the viscosity which was estimated as the difference of the viscosities determined by the rotational and oscillation mode. This difference of viscosities shows a pronounced point of inflection in any series depending on the amount of glycerol added, i. e. the hydroxyl functionality, generally in the range of 5\% of glycerol or a corresponding hydroxyl functionality of 2.08. The point of inflection was shown to be dependent on the amount of adipic acid added as a viscosity reducer. This points to the fact that the branching of the oligomer chain is responsible for the build-up of superstructures in the polyols and, hence, the formation of the main portion of structural or non-Newton'ian viscosity whereas an increased addition of adipic acid decreases the formation of superstructures in the range of triols investigated. The build-up of superstructures as measured by the difference of viscosity measurements in two modes has to be strictly avoided so as to use the polyols without technical problems in the fields of the applications anticipated. The polyols are useful to produce polyurethanes in the fields of light stable coatings, cast resins e. g. as heels, reinforced cast resins or high quality rigid foams.

\section{Acknowledgement}

The authors are grateful for financial support of the studies by Lausitzer Edelstahltechnik GmbH, DoberlugKirchhain, Germany. The authors thank Recyclit GmbH, Wildau, Germany, for placing at their disposal diethylene glycol, glycerol and adipic acid free of charge.

\section{References}

[1] Grigsby, R. A., Liquid Terephthalic Ester Polyols, EP 0154079 (29.10.1984/11.09.1985)

[2] Grigsby, R. A., Liquid Terephthalic Ester Polyols and Polyisocyanurate Foams therefrom, US 4,469,824 (18.11.1983/04.09.1984)

[3] Peterson, D., Apparatus and Method for Converting Polyethylene Terephthalate into Polyester Polyols, US patent 6,048,907 (23.08.1999/11.04.2000)

[4] Evtimova, R./Lozeva, Y./Schmidt, K-H./Wotzka, M./ Wagner, P./Behrendt, G., Polyester Polyols From Waste PET Bottles For Polyurethane Rigid Foams, Wissenschaftliche Beiträge der Technischen Fachhochschule Wildau 2003, 19-25

[5] Langenstraßen, R./Fulev, S./Apel, A./Gebert, B./Lehmann, D./Behrendt, G., Entwicklung einer Anlage zur kontinuierlichen Herstellung von PET-RecyclingPolyolen, Wissenschaftliche Beiträge der Technischen Fachhochschule Wildau 2006, 55-64

[6] Vaidya, U. R./Nadkarni, V. M., Polyester Polyols for Polyurethanes from PET Waste, J. Appl. Polym. Sci. 35, 775-785 (1988)

[7] Vaidya, U. R./Nadkarni, V. M., Polyester polyols from PET waste: effect of glycol type on kinetics of polyesterification, J. Appl. Polym. Sci. 38, 1179-1190 (1991)

[8] Reck, W., Verfahren zur Herstellung von aromatischen Polyesterpolyolen sowie aromatische Polyesterpolyole, DE-OS 19963731 (24.12.1999/05.07.2001)

[9] Langenstraßen, R./Fulev, S./Apel, A./Gebert, B./Lehmann, D./Behrendt, G., Entwicklung der Grundlagen für eine Laboranlage zur kontinuierlichen Herstellung von PET-Recycling-Polyolen, Wiss. Beitr. Techn. Fachhochsch. Wildau 2004, 34-45

[10] Boyadzhiev, M./Fulev, S./Langenstraßen, R./Evtimova, R./Behrendt, G., Investigation of the catalysis of the transesterification of PET, to be published in J. Univ. Chem. Technol. Metallurgy

[11] Fulev, S., Recycling of PET Wastes - Investigation of the Transesterification Reaction, Ph. D. dissertation, Sofia, 2007

[12] Stoycheva, V./Boyadzhiev, M./Langenstraßen, R./Behrendt, G., Polyurethanes Based on Aromatic Polyester Polyols with Varying Hydroxyl Functionality, paper to be published in J. Univ. Chem. Technol. Metallurgy

[13] Stoycheva, V./Staabs, B.(Recyclit GmbH), Neue Polyurethanharze und Verfahren zu ihrer Herstellung, patent application DE 102006038259.5 (08.08.2006)

[14] Peshkov, V./Naber, B. W./Schmidt, K.-H. (Recyclit $\mathrm{GmbH}$ ), Verfahren zur Herstellung neuer, flammgeschützter Polyurethane, patent application DE 102006 058400.7 (07.12.2006)

[15] Langenstraßen, R./Schmidt, K.-H., Entwicklung von Isolationsmaterialien aus tief- und hochtemperaturbeständigen Polyurethan-Hartschaumstoffen auf der Basis von aromatischen Polyesteralkoholen, final report in the InnoRegio project FIRM, Teilthema 9, Wildau, 2006 


\section{Literature}

in alphabetical order

Boyadzhiev, M./Fulev, S./Langenstraßen, R./Evtimova, R./ Behrendt, G., Investigation of the catalysis of the transesterification of PET, to be published in J. Univ. Chem. Technol. Metallurgy

Evtimova, R./Lozeva, Y./Schmidt, K.-H./Wotzka, M./Wagner, P./Behrendt, G., Polyester Polyols From Waste PET Bottles For Polyurethane Rigid Foams, Wissenschaftliche Beiträge der Technischen Fachhochschule Wildau 2003

Fulev, S., Recycling of PET Wastes - Investigation of the Transesterification Reaction, Ph. D. dissertation, Sofia, 2007

Grigsby, R. A., Liquid Terephthalic Ester Polyols, EP 0154079 $(29.10 .1984 / 11.09 .1985)$

Grigsby, R. A., Liquid Terephthalic Ester Polyols and Polyisocyanurate Foams therefrom, US 4,469,824 (18.11.1983/ 04.09.1984)

Langenstraßen, R./Fulev, S./Apel, A./Gebert, B./Lehmann, D./Behrendt, G., Entwicklung der Grundlagen für eine Laboranlage zur kontinuierlichen Herstellung von PETRecycling-Polyolen, Wissenschaftliche Beiträge der Technischen Fachhochschule Wildau 2004

Langenstraßen, R./Fulev, S./Apel, A./Gebert, B./Lehmann, D./Behrendt, G., Entwicklung einer Anlage zur kontinuierlichen Herstellung von PET-Recycling-Polyolen, Wissenschaftliche Beiträge der Technischen Fachhochschule Wildau 2006

Langenstraßen, R./Schmidt, K.-H., Entwicklung von Isolationsmaterialien aus tief- und hochtemperaturbeständigen Polyurethan-Hartschaumstoffen auf der Basis von aromatischen Polyesteralkoholen, final report in the InnoRegio project FIRM, Teilthema 9, Wildau, 2006

Peshkov, V./Naber, B. W./Schmidt, K.-H. (Recyclit GmbH), Verfahren zur Herstellung neuer, flammgeschützter Polyurethane, patent application DE 102006058400.7 (07.12.2006)

Peterson, D., Apparatus and Method for Converting Polyethylene Terephthalate into Polyester Polyols, US patent 6,048,907 (23.08.1999/11.04.2000)

Reck, W., Verfahren zur Herstellung von aromatischen Polyesterpolyolen sowie aromatische Polyesterpolyole, DEOS 19963731 (24.12.1999/05.07.2001)

Stoycheva, V./Boyadzhiev, M./Langenstraßen, R./Behrendt, G., Polyurethanes Based on Aromatic Polyester Polyols with Varying Hydroxyl Functionality, paper to be published in J. Univ. Chem. Technol. Metallurgy

Stoycheva, V./Staabs, B. (Recyclit GmbH), Neue Polyurethanharze und Verfahren zu ihrer Herstellung, patent application DE 102006038259.5 (08.08.2006)

Vaidya, U. R./Nadkarni, V. M., Polyester Polyols for Polyurethanes from PET Waste, J. Appl. Polym. Sci. 35, 775-785 (1988)

Vaidya, U. R./Nadkarni, V. M., Polyester polyols from PET waste: effect of glycol type on kinetics of polyesterification, J. Appl. Polym. Sci. 38, 1179-1190 (1991)

\section{Authors}

Dipl.-Chem. Marin Boyadzhiev

Wildau University of Applied Sciences

Tel. +49 3375 508-406

marin.boyadzhiev@tfh-wildau.de

Dr. Rainer Langenstraßen

Wildau University of Applied Sciences

Tel. +49 3375 508-502

rainer.langenstrassen@tfh-wildau.de

Prof. Dr. Rozeta Eftimova

University of Chemical Technology and Metallurgy

8 St. Kliment Ohridski blvd.

1756 Sofia

Bulgaria

Prof. Dr. Sanchy Nenkova

University of Chemical Technology and Metallurgy

8 St. Kliment Ohridski blvd.

1756 Sofia

Bulgaria

Tel. +3592 8685493, +35928163101

\section{Prof. Dr. Gerhard Behrendt}

Wildau University of Applied Sciences

Tel. +493375 508-591

gerhard.behrendt@tfh-wildau.de 